\title{
Roles of Small Polyetherimide Moieties on Thermal Stability and Fracture Toughness of Epoxy Blends
}

\author{
Seul-Yi Lee ${ }^{1}$, Min-Joo Kang ${ }^{1}$, Seong-Hwang Kim ${ }^{1}$, Kyong Yop Rhee ${ }^{2, *}$, Jong-Hoon Lee ${ }^{1}$ and Soo-Jin Park ${ }^{1, *}$ \\ 1 Department of Chemistry, Inha University, 100 Inharo, Incheon 22212, Korea; leesy1019@inha.ac.kr (S.-Y.L.); \\ sa-rahlunar@naver.com (M.-J.K.); seonghwangkim@inha.edu (S.-H.K.); boy834@naver.com (J.-H.L.) \\ 2 Department of Mechanical Engineering, College of Engineering, Kyung Hee University, \\ 1732 Deogyeong-daero, Yongin 17104, Korea \\ * Correspondence: rheeky@khu.ac.kr (K.Y.R.); sjpark@inha.ac.kr (S.-J.P.); \\ Tel.: +82-31-201-2565 (K.Y.R.); +82-32-876-7234 (S.-J.P.)
}

check for updates

Citation: Lee, S.-Y.; Kang, M.-J.; Kim S.-H.; Rhee, K.Y.; Lee, J.-H.; Park, S.-J. Roles of Small Polyetherimide Moieties on Thermal Stability and Fracture Toughness of Epoxy Blends. Polymers 2021, 13, 3310. https:// doi.org/10.3390/polym13193310

Academic Editor: Filippo Berto

Received: 1 September 2021

Accepted: 26 September 2021

Published: 28 September 2021

Publisher's Note: MDPI stays neutral with regard to jurisdictional claims in published maps and institutional affiliations.

Copyright: (c) 2021 by the authors. Licensee MDPI, Basel, Switzerland. This article is an open access article distributed under the terms and conditions of the Creative Commons Attribution (CC BY) license (https:// creativecommons.org/licenses/by/ $4.0 /)$.
Abstract: Bisphenol A diglycidyl ether (DGEBA) was blended with polyetherimide (PEI) as a thermoplastic toughener for thermal stability and mechanical properties as a function of PEI contents. The thermal stability and mechanical properties were investigated using a thermogravimetric analyzer (TGA) and a universal test machine, respectively. The TGA results indicate that PEI addition enhanced the thermal stability of the epoxy resins in terms of the integral procedural decomposition temperature (IPDT) and pyrolysis activation energy $\left(E_{\mathrm{t}}\right)$. The IPDT and $E_{\mathrm{t}}$ values of the DGEBA/PEI blends containing $2 \mathrm{wt} \%$ of PEI increased by $2 \%$ and $22 \%$, respectively, compared to those of neat DGEBA. Moreover, the critical stress intensity factor and critical strain energy release rate for the DGEBA/PEI blends containing $2 \mathrm{wt} \%$ of PEI increased by $83 \%$ and $194 \%$, respectively, compared to those of neat DGEBA. These results demonstrate that PEI plays a key role in enhancing the flexural strength and fracture toughness of epoxy blends. This can be attributed to the newly formed semi-interpenetrating polymer networks (semi-IPNs) composed of the epoxy network and linear PEI.

Keywords: epoxy resins; polyetherimide; thermal stability; fracture toughness

\section{Introduction}

Epoxy is extensively used as a typical thermosetting resin. Epoxy resin is widely used as adhesives, high-performance coatings, packaging, and lamination materials because it exhibits excellent chemical stability, low shrinkage, good adhesion to various metals, good thermal stability, and good mechanical properties [1-6]. However, from the perspective of high-performance engineering applications, pure epoxy resin possesses some limitations, including poor crack resistance and inherent brittleness with the high cross-linking density for curing. To overcome these problems, several methodologies, including the integration of a second phase (e.g., thermoplastics and inorganic nonparties), have been explored to improve the fracture toughness and strength in modified epoxy systems. Among the methodologies, the formation of an interpenetrating polymer network (IPN) via in situ polymerization of the toughener component has gained significant attention for obtaining a synergistic combination of desirable properties of two and/or more polymers [7]. IPN are special blends defined as mixtures of two or more cross-linked polymer networks with intermolecular interlocking, rather than chemical bonds. The network interlocking occurs during the curing process and affects the physical properties of the blends.

Since the term of "IPN" was first introduced by John Millar in 1960, various studies have reported about IPN-based epoxy systems incorporating thermoplastic polymers, such as polysurfone (PSF), polyethersulfone (PES), polycarbonate (PC), polyetheretherketone $(\mathrm{PEEK})$, and polyetherimide (PEI), and have demonstrated the enhancement in mechanical properties (i.e., fracture toughness) of epoxy resins [8-10]. 
Lee et al. [11] reported that the fracture toughness of PES/epoxy blends increased by up to $11 \%$ due to the formation of semi-IPN structures. Wang et al. [12] demonstrated the synthesis of a toughening agent based on a hyper-branched polyester with flexible chain blocking. The toughening agent improved the bending strength and impact strength of the blends by $122 \%$ and $184 \%$, respectively, which was associated with the formation of IPN between the flexible chain of the toughener and epoxy matrix. Liu et al. [13] prepared semi-IPN blends of epoxy and polyimide without the aid of any solvents and exhibited improved processability, as evidenced by the low viscosity onset temperature and reduced gelatin time at $200{ }^{\circ} \mathrm{C}$. Furthermore, due to the newly formed strong networks (semi-IPN) in the epoxy system, outstanding mechanical properties were displayed: impact strength of $22-63 \mathrm{~kJ} \cdot \mathrm{m}^{-2}$, flexural strength of 156-172 MPa, and tensile strength of 78-85 MPa.

$\mathrm{PEI}$ is an amorphous engineering thermoplastic, and compared to other polyimides, it affords a higher glass transition temperature $\left(T_{\mathrm{g}}\right)$ of $\approx 215^{\circ} \mathrm{C}$, higher strength and rigidity at elevated temperatures, higher moisture resistance, lower shrinkage, etc., thereby showing a wider range of processing capabilities. Recently, PEI has emerged as a promising candidate for enhancing the mechanical properties of epoxy systems for engineering applications due to its good compatibility and miscibility with epoxy resins. PEI has been reported to enhance the interfacial adhesion between the two phases by forming a strong network, i.e., semi-IPN structures, which increases the thermal and mechanical properties of the resultant epoxy system. These improve the stress transfers at the interfaces between PEI and epoxy without significantly decreasing the modulus or $T_{\mathrm{g}}$ and resistance to solvents and radiation [14-17].

In this study, DGEBA/PEI blends were prepared with varying PEI content. PEI was added to epoxy resin as a thermoplastic toughener to investigate mechanical behaviors through flexural strength and fracture toughness testing in the prepared blends. The integral procedural decomposition temperature (IPDT) and pyrolysis activation energy $\left(E_{t}\right)$ values of the DGEBA/PEI blends were higher than those of neat epoxy by $2 \%$ and $22 \%$, respectively. Furthermore, after the introduction of $2 \mathrm{wt} \%$ of PEI into the epoxy, the $K_{\text {IC }}$ and $G_{I C}$ values increased by $83 \%$ and $194 \%$, respectively. Our experiment confirms that the thermal stability and mechanical properties of epoxy can be improved by adding PEI as a toughener. Thus, these results imply a great potential of PEI-loaded epoxy blends for the applications in civil and structural engineering. We believe that this work provides a guidance for utilizing thermoplastic polymers, which could be a powerful strategy to extend the tuning range in the future design and manufacturing of epoxy blends.

\section{Materials and Methods}

\subsection{Materials}

Bisphenol A diglycidyl ether (DGEBA; YD 128) as the epoxy matrix was supplied by Kukdo Chemical Co. (Seoul, Korea) its epoxide-equivalent weight was 185-190 g.equiv ${ }^{-1}$. PEI as a thermoplastic toughener was supplied by Sigma-Aldrich Co. (St. Louis, MO, USA), with average molecular weights of $\mathrm{Mw}=25,000$ and $\mathrm{Mn}=10,000$, viscosity of $15,000 \mathrm{mPa} \cdot \mathrm{s}$ at $50{ }^{\circ} \mathrm{C}$, and density of $1.27 \mathrm{~g} \cdot \mathrm{cm}^{-3}$ at $25^{\circ} \mathrm{C} \cdot 4,4^{\prime}$-Diaminodiphenylmethane (DDM) and methylene chloride (MC), as the curing agent and solvent, respectively, were obtained from Sigma-Aldrich Co. The chemical structures of DGEBA, PEI, and DDM are shown in Figure 1.

\subsection{Preparation of Blends}

DGEBA/PEI blends were prepared with a weight ratio of $1-4 \mathrm{wt} \%$. PEI was dissolved in MC by stirring at room temperature for $4 \mathrm{~h}$. DGEBA was mixed with the PEI solution at $100{ }^{\circ} \mathrm{C}$ for $24 \mathrm{~h}$, and the mixture was placed in a vacuum oven to evaporate the solvent. This mixture was additionally stirred at $60^{\circ} \mathrm{C}$ to completely remove the bubbles and residual solvent. DDM was added into the mixture, and then, the final mixture was injected into a mold. The obtained blends were transferred to a convection oven for curing at $110^{\circ} \mathrm{C}$ for $1 \mathrm{~h}, 140{ }^{\circ} \mathrm{C}$ for $2 \mathrm{~h}$, and $170^{\circ} \mathrm{C}$ for $1 \mathrm{~h}$. Figure 2 illustrates the preparation method for the DGEBA/PEI blends. 


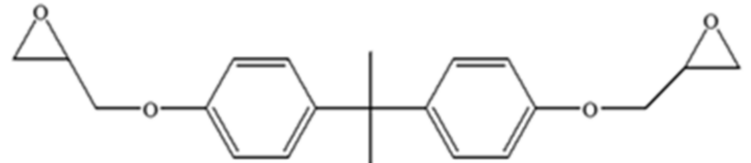

Diglycidyl ether of bisphenol A (DGEBA)<smiles>Nc1ccc(Cc2ccc(N)cc2)cc1</smiles>

4,4'-Diaminodiphenylmethane (DDM)<smiles>Cc1cccc(N2C(=O)c3ccc(Oc4ccc(C(C)(C)c5ccc(Oc6ccc7c(c6)C(=O)C(C)(C)C7=O)cc5)cc4)cc3C2=O)c1</smiles>

Polyetherimide (PEI)

Figure 1. Chemical structures of DGEBA, PEI, and DDM.

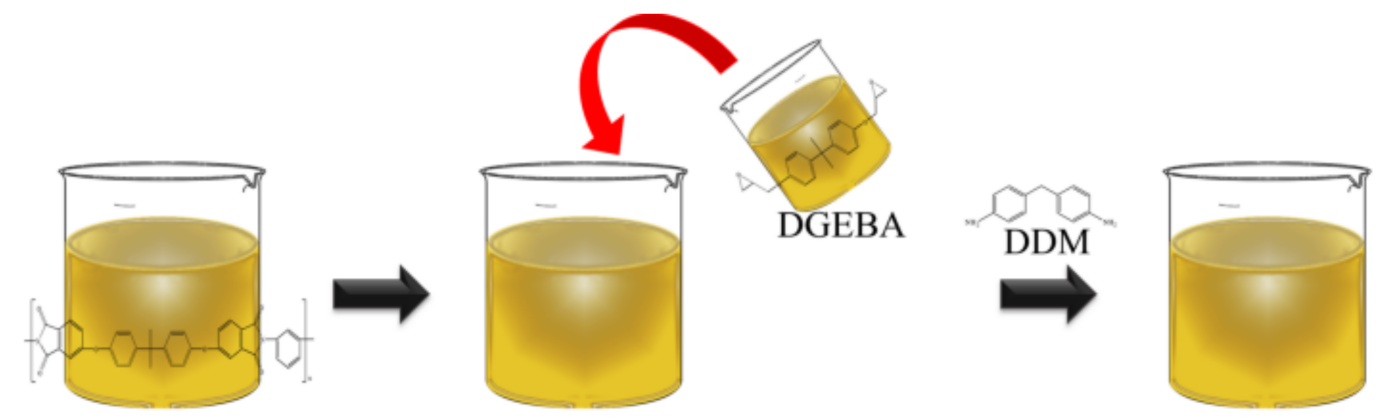

PEI dissolved in MC
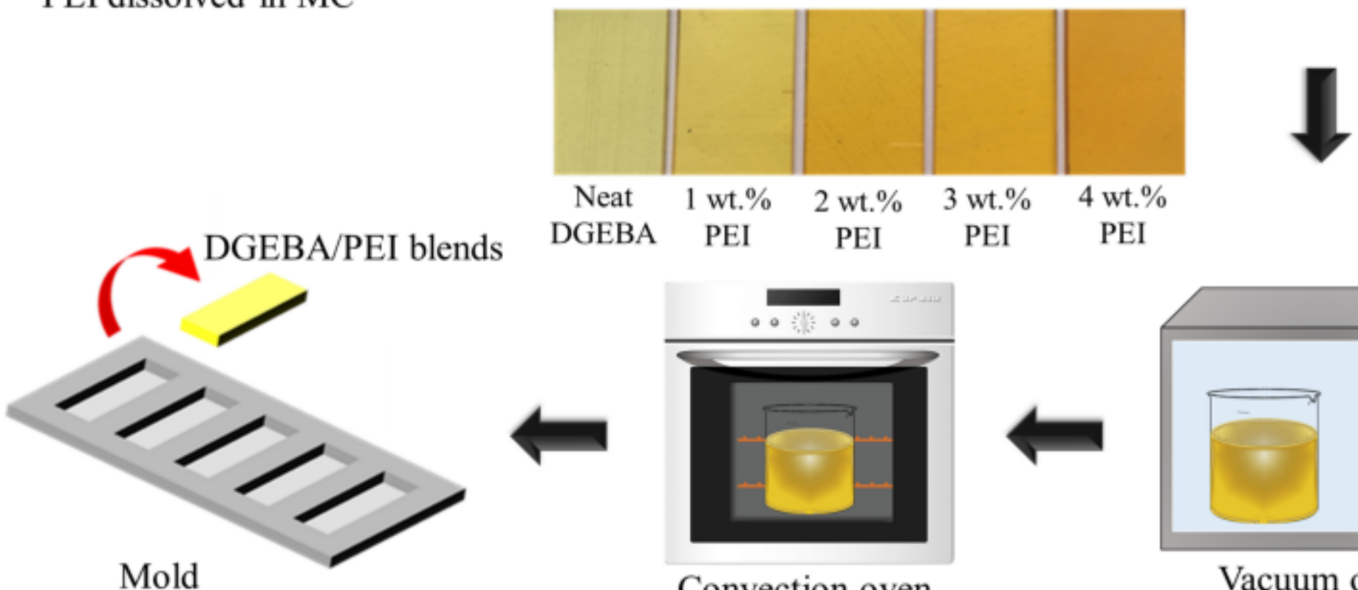
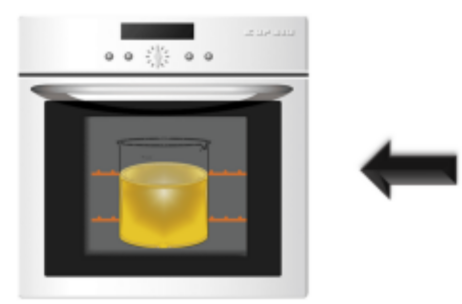

Convection oven

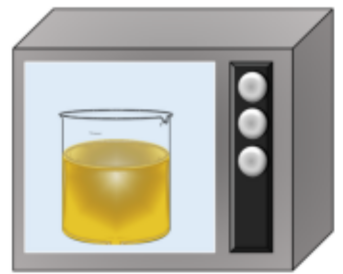

Vacuum oven

Figure 2. Schematic diagram for the preparation of DGEBA/PEI blends.

\subsection{Characterization and Measurements}

Fourier transform-infrared (FT-IR, BRUKER VERTEX 80 V, BRUKER, Billerica, MA, USA) spectra of DGEBA/PEI blends were obtained by background subtraction and ATR corrected in the range from 800 to $4000 \mathrm{~cm}^{-1}$. The thermal stability of DGEBA/PEI blends was analyzed using a thermogravimetric analyzer (TGA, NETZSCH TG209 F3, ETZSCH, Selb, Germany). The analysis was conducted under nitrogen flow with increasing temperature from 50 to $800{ }^{\circ} \mathrm{C}$ at a heating rate of $10^{\circ} \mathrm{C} \cdot \mathrm{min}^{-1}$. The critical stress intensity factor $\left(K_{\mathrm{IC}}\right)$, critical strain energy release rate $\left(\mathrm{G}_{\mathrm{IC}}\right)$, and fracture toughness of the prepared specimen were measured using a universal test machine according to ASTM D5045-95. The sample size of the single edge notch specimen was $5 \times 10 \times 50 \mathrm{~mm}^{3}$, and the cross-head speed was $10 \mathrm{~mm} \cdot \mathrm{min}^{-1}$. After performing the $K_{\mathrm{IC}}$ fracture toughness tests, the fractured 
surfaces were observed using a scanning electron microscope (SEM, HITACHI SU8010) to investigate the DGEBA/PEI blend morphology.

\section{Results and Discussion}

\subsection{Curing of the DGEBA/PEI Blends}

Figure 3a shows the FT-IR spectra of the DGEBA epoxy resin, cured neat DGEBA, and DGEBA/PEI blends containing $2 \mathrm{wt} \%$ of PEI. In addition, the FT-IR spectra of the PEI is given in Figure S1. The characteristic absorption peaks of the epoxide and hydroxyl groups appeared at 906 and $3429 \mathrm{~cm}^{-1}$, respectively [18,19]. For the DGEBA/PEI blends, new peaks were observed at $1716 \mathrm{~cm}^{-1}$, which can be attributed to stretching vibrations of the imide group (typical of imide carbonyl asymmetrical and symmetrical stretch). The peaks of the epoxide group for the cured DGEBA and DGEBA/PEI blends significantly decreased after the curing reaction. Moreover, the peaks of the hydroxyl stretching vibrations increased due to the reaction between the amine group in DDM and the epoxide group to form a hydroxyl group. Partial spectra of the neat DGEBA and the DGEBA/PEI blends in the 3000-3800 $\mathrm{cm}^{-1}$ wavenumber range are shown in Figure $3 \mathrm{~b}$. The peak of the hydroxyl stretching vibrations for the DGEBA/PEI blends shifted to lower wavenumbers after PEI addition. This suggests that intermolecular interactions, such as hydrogen bonding, occurred between the hydroxyl groups in DGEBA and carbonyl groups in PEI [20-24].

(a)

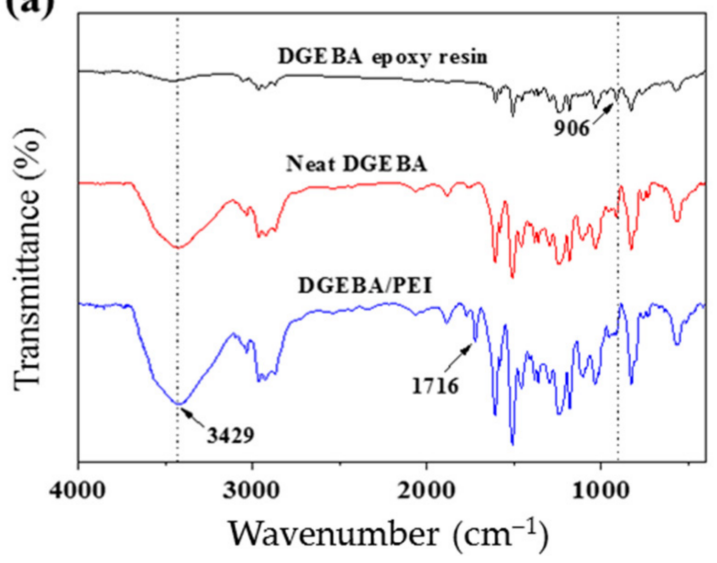

(b)

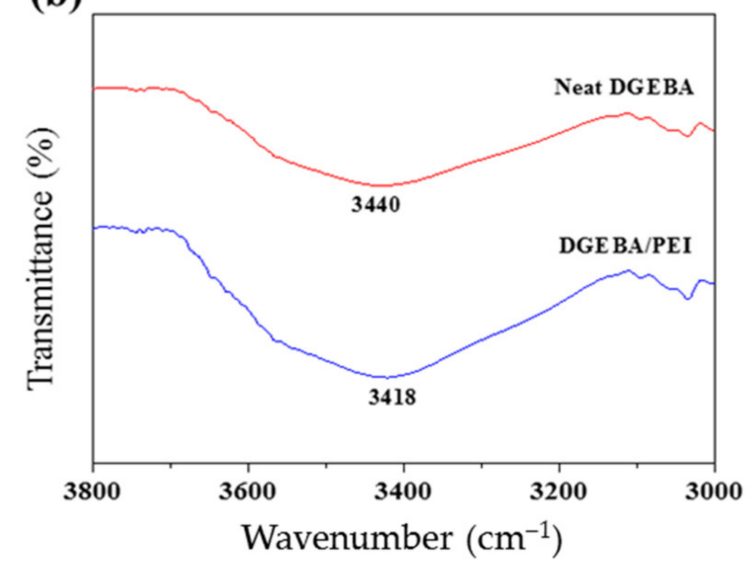

Figure 3. Curing of the DGEBA/PEI blends: (a) FT-IR spectra of DGEBA, cured neat DGEBA, and DGEBA/PEI blends containing $2 \mathrm{wt} \%$ of PEI and (b) Partial FT-IR spectra of DGEBA/PEI blends in the range of $3000-3800 \mathrm{~cm}^{-1}$.

\section{Thermal Stability of the DGEBA/PEI Blends}

Thermal stability is a critical factor on polymeric materials for processing and practical application. Figure 4 a shows the thermogravimetric curves of the neat DGEBA and DGEBA/PEI blends. As expected, the significant changes of the thermal stability studied in the work were not apparent in the presence of small moieties of PEI in the epoxy blend. However, it is found that the variation of the activation energy of decomposition can be revealed in the work, as shown in Figure $4 \mathrm{~b}$, degradation occurred between 360 and $420^{\circ} \mathrm{C}$. The thermal stability factors, including the polymer decomposition temperature (PDT), IPDT, temperatures of maximum rate of degradation $\left(T_{\max }\right)$, and $E_{\mathrm{t}}$, were calculated from the thermogravimetric results [25]. For the delineation of dynamics of thermal decomposition, kinetic parameters of IPDT that correlate with the volatile components were determined from Doyle's proposition as follows [26]:

$$
\begin{gathered}
\mathrm{IPDT}=A^{*} \times K^{*} \times\left(T_{\mathrm{f}}-T_{\mathrm{i}}\right)+T_{\mathrm{i}} \\
A^{*}=\frac{\left(S_{1}+S_{2}\right)}{\left(S_{1}+S_{2}+S_{3}\right)}
\end{gathered}
$$




$$
K^{*}=\frac{\left(S_{1}+S_{2}\right)}{S_{1}}
$$

where $A^{*}$ is the area ratio of the total experimental curve defined by the total TGA thermogram, $K^{*}$ is the coefficient of $A^{*}, T_{\mathrm{i}}$ is the initial experimental temperature, and $T_{\mathrm{f}}$ is the final experimental temperature. The inherent thermal stability of polymer blends during thermal degradation is understood by IPDT.

(a)

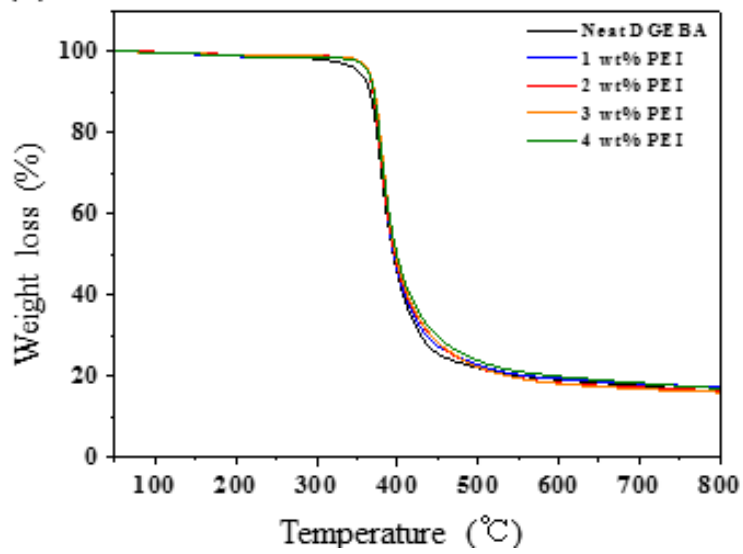

(b)

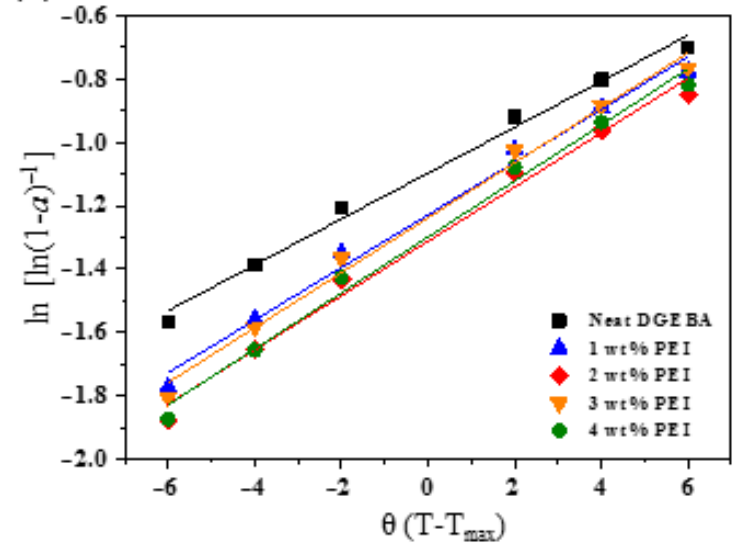

Figure 4. Thermal stability of the DGEBA/PEI blends: (a) TGA curves and (b) plots of $\ln \left[\ln (1-\alpha)^{-1}\right]$ vs. $\theta$ using the Horowitz-Metzger method [25].

For detailed investigation of the polymer blends' decomposition and activation energy of thermal degradation, the $\left(E_{\mathrm{t}}\right)$ were calculated from the TGA curves using the HorowitzMetzger method as follows [27]:

$$
\begin{gathered}
\ln \left[\ln (1-\alpha)^{-1}\right]=\frac{E_{\mathrm{t}} \theta}{R T_{\max }^{2}} \\
\alpha=\frac{W_{0}-W_{\mathrm{t}}}{W_{0}-W_{\infty}}
\end{gathered}
$$

where $\alpha$ is the decomposition fraction, $\theta=T-T_{\max }, R$ is the universal gas constant, $W_{\mathrm{t}}$ is the actual mass of the sample, $W_{0}$ is the initial mass of the sample, and $W_{\infty}$ is the final mass of the sample. Figure $4 \mathrm{~b}$ shows the plots of $\ln \left[\ln (1-\alpha)^{-1}\right]$ vs. $\theta$. The $E_{\mathrm{t}}$ value was calculated from the slope of the straight lines using Equation (4).

Table 1 summarizes the calculated PDT, IPDT, $T_{\max }$, and $E_{\mathrm{t}}$ values of the neat DGEBA and DGEBA/PEI blends. The PDT and IPDT values of the blends slightly increased due to PEI addition. The $T_{\max }$ value of the DGEBA/PEI blends was similar to that of neat DGEBA. The $E_{\mathrm{t}}$ value of neat DGEBA was $256.3 \mathrm{~kJ} \cdot \mathrm{mol}^{-1}$, whereas that of the blends was significantly higher $\left(294.1-312.8 \mathrm{~kJ} \cdot \mathrm{mol}^{-1}\right)$. This confirms that more activation energy was needed for pyrolysis, as the DGEBA/PEI blend was more stable and more difficult to decompose [28-30].

Table 1. Thermal stability parameters of the DGEBA/PEI blends.

\begin{tabular}{cccccc}
\hline Specimen & ${ }^{\mathbf{1}} \mathbf{P D T}\left({ }^{\circ} \mathbf{C}\right)$ & ${ }^{\mathbf{2}} \boldsymbol{A}^{*} \boldsymbol{K}^{\mathbf{*}}$ & ${ }^{\mathbf{3}} \mathbf{I P D T}\left({ }^{\circ} \mathbf{C}\right)$ & ${ }^{\mathbf{4}} \boldsymbol{T}_{\mathbf{m a x}}\left({ }^{\circ} \mathbf{C}\right)$ & ${ }^{\mathbf{5}} \boldsymbol{E}_{\mathbf{t}}\left(\mathbf{k J} \cdot \mathbf{m o l} \mathbf{~}^{-\mathbf{1}}\right)$ \\
\hline neat DGEBA & 364.1 & 0.81 & 399.5 & 379.9 & 256.3 \\
$1 \mathrm{wt} \%$ of PEI & 366.3 & 0.82 & 401.7 & 379.9 & 294.0 \\
$2 \mathrm{wt} \%$ of PEI & 366.8 & 0.86 & 404.4 & 379.9 & 312.8 \\
$3 \mathrm{wt} \%$ of PEI & 366.7 & 0.84 & 402.6 & 379.9 & 306.9 \\
$4 \mathrm{wt} \%$ of PEI & 366.6 & 0.81 & 401.8 & 379.9 & 303.3 \\
\hline
\end{tabular}

${ }^{1}$ PDT: Polymer decomposition temperature; ${ }^{2} A^{*} K{ }^{*}$ : Thermal stability index; ${ }^{3}$ IPDT: Integral procedural decomposition temperature; ${ }^{4} T_{\max }$ : Temperatures of maximum rate of degradation; ${ }^{5} E_{\mathrm{t}}$ : Activation energy of decomposition. 


\section{Mechanical Properties of the DGEBA/PEI Blends}

Flexural strength $(\sigma)$ and flexural modulus $\left(E_{\mathrm{b}}\right)$ of the DGEBA/PEI blends with different PEI loading amounts were also calculated, using the following Equations (6) and (7):

$$
\begin{gathered}
\sigma=\frac{3 \mathrm{P} L}{2 b d^{2}} \\
E_{\mathrm{b}}=\frac{\mathrm{L}^{3}}{4 \mathrm{bd}^{3}} \frac{\Delta \mathrm{P}}{\Delta \mathrm{m}}
\end{gathered}
$$

where $P$ is the applied peak load, $b$ is the sample width, $d$ is the specimen thickness, $L$ is the support span, $\Delta \mathrm{P}$ is the variation in force at the linear portion, and $\Delta \mathrm{m}$ is the relative deflection variation.

Figure 5 shows the flexural strength and flexural modulus of DGEBA/PEI blends. The $\sigma$ and $E_{\mathrm{b}}$ values of the blends increased with the PEI content up to $2 \mathrm{wt} \% . \sigma$ and $E_{\mathrm{b}}$ values of the blends containing $2 \mathrm{wt} \%$ of PEI were $143.3 \mathrm{MPa}$ and 2.8 GPa, respectively, which were $20 \%$ and $17 \%$ higher than those of neat DGEBA (119.7 MPa and $2.4 \mathrm{GPa}$ ).

(a)

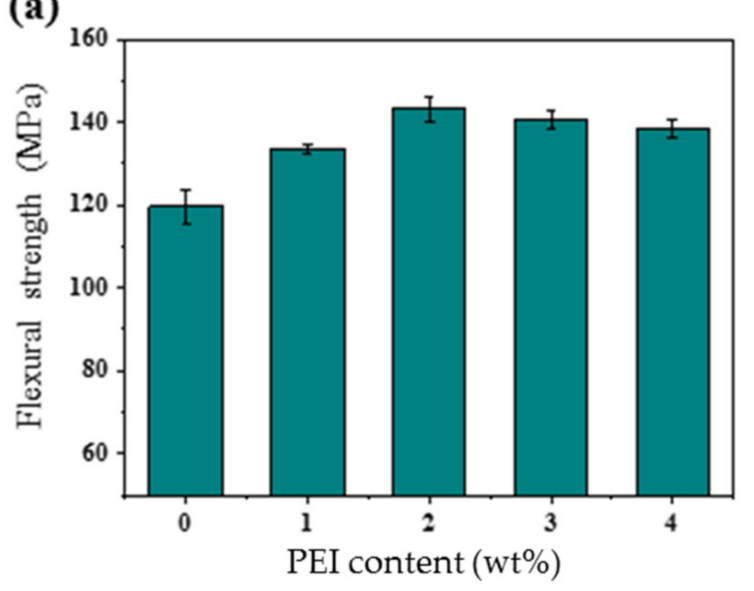

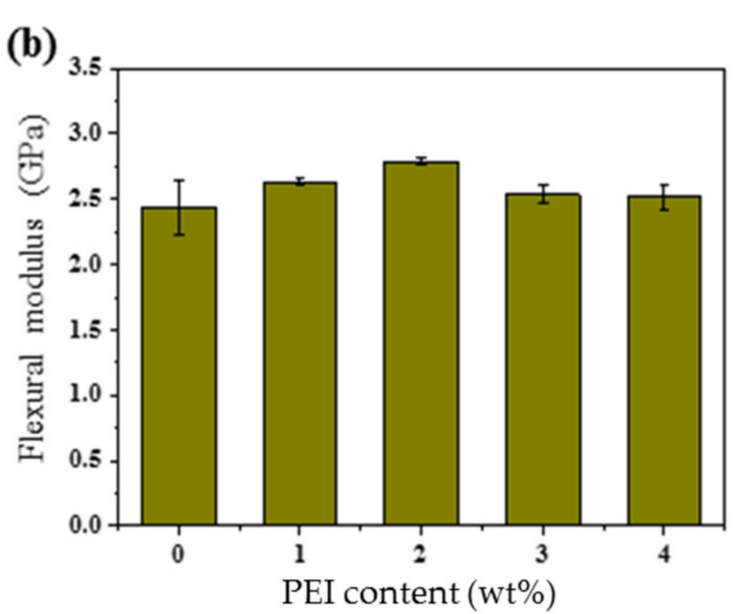

Figure 5. Flexural strengths of the DGEBA/PEI blends: (a) flexural strength and (b) flexural modulus.

The flexural strengths of DGEBA-based blends are compared in Table 2. The optimized DGEBA/PEI sample appeared to have superior flexural strength compared to other DGEBA-based blends. It appears that the PEI plays an important role as a mechanical reinforcement in improving the flexural strength, resulting from enhanced semi-IPN between the PEI and epoxy matrix.

Table 2. Comparisons of DGEBA-based blends in flexural strength.

\begin{tabular}{cccc}
\hline Specimen & Content $\mathbf{( w t} \%)$ & Flexural Strength (MPa) & References \\
\hline DGEBA/HER-HT & 12 & 84.0 & {$[31]$} \\
DGEBA/MHHPA & 70 & 131.6 & {$[32]$} \\
DGEBA/D230 & 30 & 121.0 & {$[33]$} \\
DGEBA/castor oil & 20 & 100.1 & {$[34]$} \\
DGEBA/soybean oil & 10 & 127.0 & {$[35]$} \\
DGEBA/cardanol epoxy & 20 & 80.8 & {$[36]$} \\
DGEBA/PEI & 2 & 143.3 & This work \\
\hline
\end{tabular}

Fracture toughness is a fundamental property of polymeric materials indicating the strain energy and absorbing ability of pre-fracture materials. A higher fracture toughness indicates higher resistance to crack propagation. The fracture toughness of the DGEBA/PEI blends was investigated using the $K_{\mathrm{IC}}$ and $\mathrm{G}_{\mathrm{IC}}$ values (Figure 5). The $K_{\mathrm{IC}}$ and $\mathrm{G}_{\mathrm{IC}}$ values can be calculated as follows [37-39]: 


$$
\begin{gathered}
K_{\mathrm{IC}}=\frac{P}{B W^{\frac{1}{2}}} f(a / w) \\
f(a / W)=\frac{\left.(2+a / W)\left[0.886+4.64 a / W-13.32 a / W^{2}+14.72 a / W^{3}-5.6 a / W^{4}\right)\right]}{(1-a / W)^{3 / 2}}
\end{gathered}
$$

where $P(\mathrm{~N}), a(\mathrm{~mm}), W$, and $B$ are the critical load, crack length, width, and thickness of the specimen, respectively. Moreover, $f(a / W)$ is the geometric element obtained from Equation (7).

$$
G_{\mathrm{IC}}=\frac{\left(1-v^{2}\right) \cdot K_{\mathrm{IC}}^{2}}{E}
$$

where $v$ is the Poisson's ratio (0.3), and $E$ is the tensile modulus obtained from the fracture testing [40].

Figure 6 shows the fracture toughness of the DGEBA/PEI blends as a function of the PEI content. The load-deflection curves of DGEBA/PEI blends are shown in Figure 6a. It can be seen that neat DGEBA fractured at low deflection before yielding, whereas the DGEBA/PEI blends exhibited ductile behavior with yielding and subsequent plastic deformation. The $K_{\mathrm{IC}}$ and $\mathrm{G}_{\mathrm{IC}}$ values of the blends increased with the PEI content up to $2 \mathrm{wt} \%$. The $K_{\mathrm{IC}}$ values of the blends containing the blends containing $2 \mathrm{wt} \%$ of PEI were $4.9 \mathrm{MPa} \cdot \mathrm{m}^{1 / 2}$, which were $83 \%$ higher than those of neat DGEBA (Figure $6 \mathrm{~b}$ ). Moreover, $G_{\text {IC }}$ values of the blends containing $2 \mathrm{wt} \%$ of PEI were $58.5 \mathrm{~kJ} \cdot \mathrm{m}^{-2}$, which were $194 \%$ higher than those of neat DGEBA (Figure 6c). This can be attributed to the newly formed intermolecular interaction (semi-IPN) between PEI and the epoxy matrix in the DGEBA/PEI blends. The mechanical properties, including the $K_{\text {IC }}$ and $G_{I C}$, of the DGEBA/PEI blends are indicated in Figure 6d. Here, all the DGEBA/PEI blends exhibit excellent linear relationships between the $K_{\mathrm{IC}}$ and the $\mathrm{G}_{\mathrm{IC}}$. Thus, we confirmed that the PEI particles in the epoxy matrix act as stress concentrators to absorb the external energy and mitigate the crack growth [41-46].

(a)
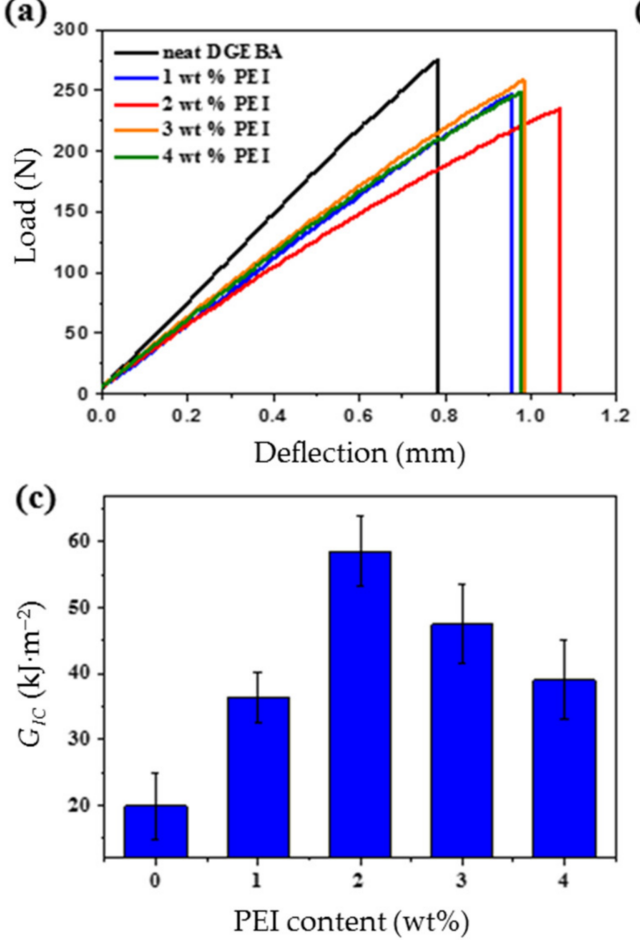

(b)
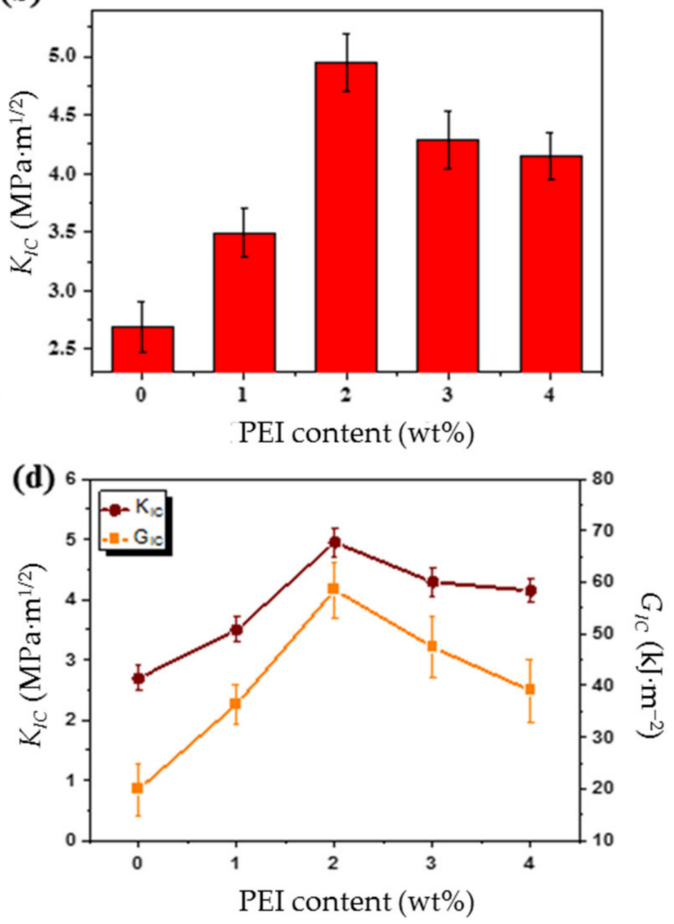

Figure 6. Fracture toughness behaviors of the DGEBA/PEI blends: (a) load-deflection curves, (b) $K_{\mathrm{IC}}$, (c) $G_{\mathrm{IC}}$, and (d) correlations between the $K_{\mathrm{IC}}$ and $G_{\mathrm{IC}}$. 
Figure 7 shows SEM images of the morphologies of the fractured surfaces for neat DGEBA and DGEBA/PEI blends after the fracture tests. It indicates the crack progression on the fracture surfaces. As shown in Figure $7 \mathrm{a}, \mathrm{d}$, neat DGEBA displayed a regular fracture surface, which is the typical characteristic of a brittle fracture. In contrast, the blends containing $2 \mathrm{wt} \%$ of PEI (Figure $7 \mathrm{~b}, \mathrm{e}$ ) showed rough surfaces, meaning a ductile fracture. However, the blends containing $4 \mathrm{wt} \%$ of PEI (Figure $7 \mathrm{c}, \mathrm{f}$ ) were shown in the structure of the separated phases. From the results, it was found that excellent semi-IPN structures were formed with the blends containing $2 \mathrm{wt} \%$ of PEI, which is closely related to the thermal stability and mechanical properties $[47,48]$.

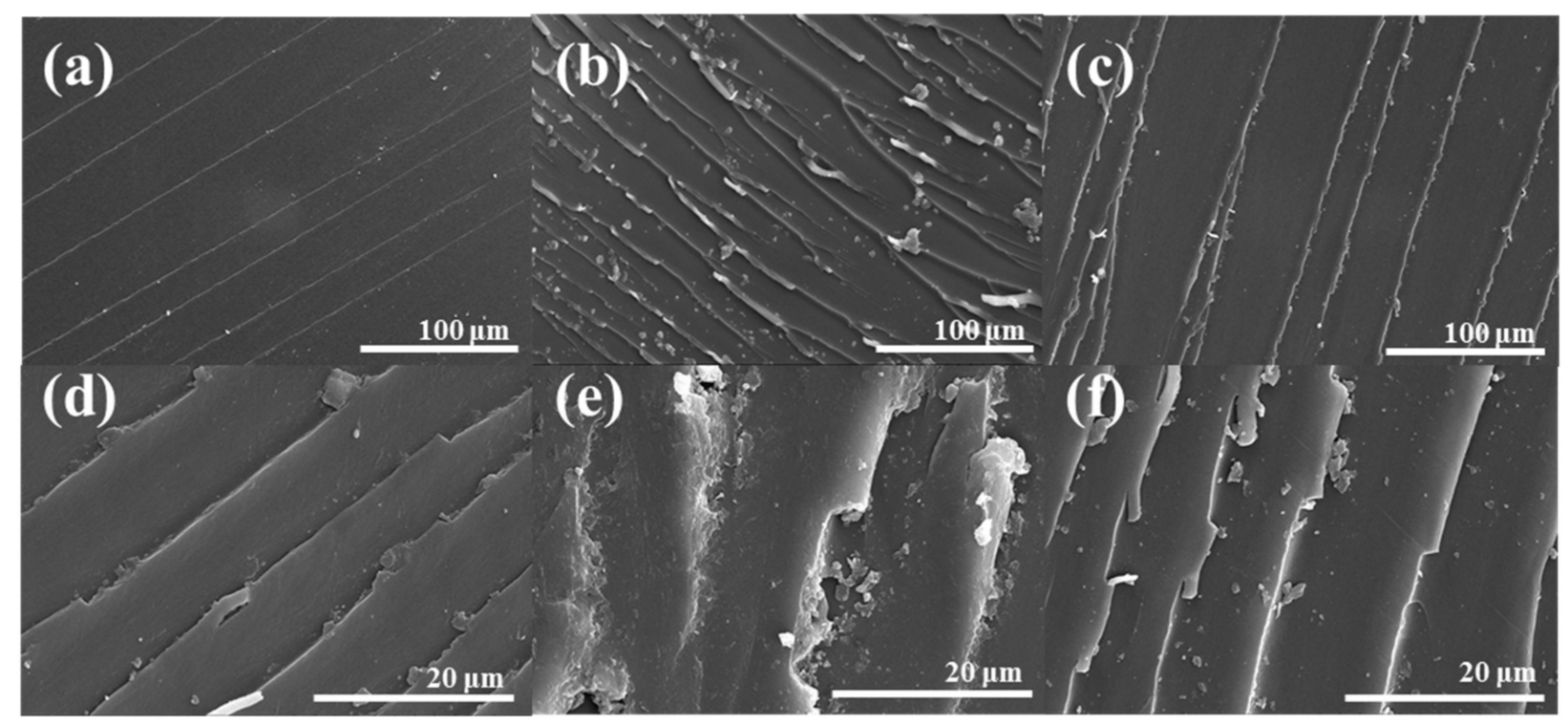

Figure 7. Fracture surface of the DGEBA/PEI blends: (a,d) neat DGEBA, (b,e) $2 \mathrm{wt} \%$ of PEI, and (c,f) $4 \mathrm{wt} \%$ of PEI.

\section{Conclusions}

In this study, we observed the thermal stability and fracture toughness of neat DGEBA and DGEBA/PEI blends. The PDT and IPDT values of the blends slightly increased with the PEI content. The $E_{\mathrm{t}}$ value of the blends significantly increased by $22 \%$ from 256.3 to $312.8 \mathrm{~kJ} \cdot \mathrm{mol}^{-1}$ after the addition of $2 \mathrm{wt} \%$ of PEI. The $K_{\mathrm{IC}}$ and $G_{\mathrm{IC}}$ values of the blends containing $2 \mathrm{wt} \%$ of PEI were $83 \%$ and $194 \%$, respectively, higher than those of neat DGEBA, which is associated with the increase in the activation energy of decomposition in thermal stability studies. The SEM images indicated that the surfaces of the DGEBA/PEI blends were rougher than those of neat DGEBA, accounting for their excellent fracture toughness. In summary, the addition of PEI to DGEBA significantly improved the fracture toughness due to the newly formed semi-IPN structures, which resulted from the combination of two noncompatible polymers. Thus, PEI plays an important role in enhancing the interfacial adhesion of epoxy. Therefore, the applications of the obtained DGEBA/PEI blends should be extended, such as heat resistant adhesive, surface coating, high performance blends, and electrical and electronic encapsulation.

Supplementary Materials: The following are available online at https:/ / www.mdpi.com/article/ 10.3390/polym13193310/s1, Figure S1: FT-IR spectrum of PEI.

Author Contributions: Conceptualization, writing and revision, and supervision by S.-Y.L.; investigation, writing - original draft by M.-J.K., S.-H.K. and J.-H.L.; supervision, project administration, and funding acquisition by S.-J.P. and K.Y.R. All authors have read and agreed to the published version of the manuscript. 
Funding: This work was supported by the Technology Innovation Program (or Industrial Strategic Technology Development Program-Development of technology on materials and components) (20010106, Adhesives with low water permeability and low outgassing) funded by the Ministry of Trade, Industry \& Energy (MOTIE, Korea) and supported by the Technological Innovation R\&D Program (S2849653) funded by the Small and Medium Business Administration (SMBA, Korea).

Institutional Review Board Statement: Not applicable.

Informed Consent Statement: Not applicable.

Data Availability Statement: Not applicable.

Conflicts of Interest: The authors declare that they have no competing interests.

\section{References}

1. Jones, R.; Klein, J.; Donald, A. Mutual diffusion in a miscible polymer blend. Nature 1986, 321, 161-162. [CrossRef]

2. Chen, T.; Fang, L.; Li, X.; Gao, D.; Lu, C.; Xu, Z. Self-healing polymer coatings of polyurea-urethane/epoxy blends with reversible and dynamic bonds. Prog. Org. Coat. 2020, 147, 105876. [CrossRef]

3. Ji, F.; Zhou, Y.; Yang, Y. Tailoring the structure and properties of epoxy-polyurea vitrimers via controllable network reconfiguration. J. Mater. Chem. A 2021, 9, 7172-7179. [CrossRef]

4. Yue, J.; He, L.; Zhao, P.; Gu, Y. Engineering Benzoxazine/Epoxy/Imidazole Blends with Controllable Microphase Structures for Toughness Improvement. ACS Appl. Polym. Mater. 2020, 2, 3458-3464. [CrossRef]

5. Kim, S.-H.; Rhee, K.Y.; Park, S.-J. Amine-terminated chain-grafted nanodiamond/epoxy nanocomposites as interfacial materials: Thermal conductivity and fracture resistance. Compos. Part B Eng. 2020, 192, 107983. [CrossRef]

6. Kim, S.H.; Park, S.J.; Rhee, K.Y.; Park, S.-J. Effects of ozonized carbon black on fracture and post-cracking toughness of carbon fiber-reinforced epoxy composites. Compos. Part B Eng. 2019, 177, 107379. [CrossRef]

7. Farooq, U.; Teuwen, J.; Dransfeld, C. Toughening of epoxy systems with interpenetrating polymer network (IPN): A review. Polymers 2020, 12, 1908. [CrossRef] [PubMed]

8. Millar, J. 263. Interpenetrating polymer networks. Styrene-divinylbenzene copolymers with two and three interpenetrating networks, and their sulphonates. J. Chem. Soc. 1960, 1311-1317. [CrossRef]

9. Meng, C.; Huang, S.; Han, D.; Ren, S.; Wang, S.; Xiao, M. Semi-interpenetrating Network Membrane from PolyethyleneimineEpoxy Resin and Polybenzimidazole for HT-PEM Fuel Cells. Adv. Polym. Technol. 2020, 2020, 3845982. [CrossRef]

10. Li, H.; Gan, W.; Zhao, L.; Li, S. Studies on the Phase Separation of a Polyetherimide Modified Epoxy Resin. VI. Effect of Surface Energy on Reaction-Induced Phase Separation of Epoxy Resin Modified with Polyetherimide. J. Macromol. Sci. Part A 2003, 40, 833-846. [CrossRef]

11. Lee, S.-E.; Jeong, E.; Lee, M.Y.; Lee, M.-K.; Lee, Y.-S. Improvement of the mechanical and thermal properties of polyethersulfonemodified epoxy composites. J. Ind. Eng. Chem. 2016, 33, 73-79. [CrossRef]

12. Wang, Z.; Zhang, X.; Weng, L.; Liu, L. Low dielectric constant and high toughness epoxy resin based on hyperbranched polyester grafted by flexible chain modified. J. Mater. Sci. Mater. Electron. 2019, 30, 5936-5946. [CrossRef]

13. Liu, J.; Fan, W.; Lu, G.; Zhou, D.; Wang, Z.; Yan, J. Semi-interpenetrating polymer networks based on cyanate ester and highly soluble thermoplastic polyimide. Polymers 2019, 11, 862. [CrossRef] [PubMed]

14. Zhang, J.; Xie, X. Influence of addition of silica particles on reaction-induced phase separation and properties of epoxy/PEI blends. Compos. Part B Eng. 2011, 42, 2163-2169. [CrossRef]

15. Woo, E.M. FT-IR analysis of the effects of polymeric additives on epoxy homopolymerization or hydroxyl exchanges. Polym. J. 1997, 29, 523-528. [CrossRef]

16. Buketov, A.; Maruschak, P.; Sapronov, O.; Zinchenko, D.; Yatsyuk, V.; Panin, S. Enhancing Performance Characteristics of Equipment of Sea and River Transport by Using Epoxy Composites. Transport 2016, 31, 333-342. [CrossRef]

17. Buketov, A.; Smetankin, S.; Maruschak, P.; Yurenin, K.; Sapronov, O.; Matvyeyev, V.; Menou, A. New Black-Filled Epoxy Coatings for Repairing Surface of Equipment of Marine Ships. Transport 2020, 35, 679-690.

18. Musto, P.; Martuscelli, E.; Ragosta, G.; Russo, P.; Scarinzi, G.; Villano, P. FTIR spectroscopy and physical properties of an epoxy/bismaleimide IPN system. J. Mater. Sci. Mater. Electron. 1998, 33, 4595-4601. [CrossRef]

19. Musto, P.; Karasz, F.; MacKnight, W. Fourier transform infra-red spectroscopy on the thermo-oxidative degradation of polybenzimidazole and of a polybenzimidazole/polyetherimide blend. Polymer 1993, 34, 2934-2945. [CrossRef]

20. Jang, J.; Lee, W. Polyetherimide-modified high performance epoxy resin. Polym. J. 1994, 26, 513-525. [CrossRef]

21. Cole, K.C. A new approach to modeling the cure kinetics of epoxy/amine thermosetting resins. 1. Mathematical development. Macromolecules 1991, 24, 3093-3097. [CrossRef]

22. Xu, L.; Schlup, J.R. Etherification versus amine addition during epoxy resin/amine cure: An in situ study using near-infrared spectroscopy. J. Appl. Polym. Sci. 1998, 67, 895-901. [CrossRef]

23. Price, C.C.; Carmelite, D.D. Reactions of epoxides in dimethyl sulfoxide catalyzed by potassium t-butoxide. J. Am. Chem. Soc. 1966, 88, 4039-4044. [CrossRef] 
24. Park, S.J.; Kim, H.C. Thermal stability and toughening of epoxy resin with polysulfone resin. J. Polym. Sci. Part B Polym. Phys. 2001, 39, 121-128. [CrossRef]

25. Wu, C.S.; Liu, Y.L.; Chiu, Y.C.; Chiu, Y.S. Thermal stability of epoxy resins containing flame retardant components: An evaluation with thermogravimetric analysis. Polym. Degrad. Stab. 2002, 78, 41-48. [CrossRef]

26. Doyle, C. Estimating thermal stability of experimental polymers by empirical thermogravimetric analysis. Anal. Chem. 1961, 33, 77-79. [CrossRef]

27. Horowitz, H.H.; Metzger, G. A new analysis of thermogravimetric traces. Anal. Chem. 1963, 35, 1464-1468. [CrossRef]

28. Park, S.-J.; Jin, F.-L. Thermal stabilities and dynamic mechanical properties of sulfone-containing epoxy resin cured with anhydride. Polym. Degrad. Stab. 2004, 86, 515-520. [CrossRef]

29. Jin, F.-L.; Park, S.-J. Thermal properties of epoxy resin/filler hybrid composites. Polym. Degrad. Stab. 2012, 97, 2148-2153. [CrossRef]

30. Zhou, T.; Wang, X.; Gu, M.; Xiong, D. Study on mechanical, thermal and electrical characterizations of nano-SiC/epoxy composites. Polym. J. 2009, 41, 51-57. [CrossRef]

31. Ma, X.; Liang, Y.Y.; Xu, Z.J.; Chen, S.F.; Cheng, J.; Miao, M.H.; Zhang, D.H. The versatility of hyperbranched epoxy resins containing hexahydro-s-triazine on diglycidyl ether of bisphenol-A composites. Compos. Part B-Eng. 2020, 196, 108109. [CrossRef]

32. Ma, S.Q.; Liu, X.Q.; Fan, L.B.; Jiang, Y.H.; Cao, L.J.; Tang, Z.B.; Zhu, J. Synthesis and Properties of a Bio-Based Epoxy Resin with High Epoxy Value and Low Viscosity. Chemsuschem 2014, 7, 555-562. [CrossRef]

33. Deng, J.; Liu, X.Q.; Li, C.; Jiang, Y.H.; Zhu, J. Synthesis and properties of a bio-based epoxy resin from 2,5-furandicarboxylic acid (FDCA). RSC Adv. 2015, 5, 15930-15939. [CrossRef]

34. Sudha, G.S.; Kalita, H.; Mohanty, S.; Nayak, S.K. Biobased Epoxy Blends from Epoxidized Castor Oil: Effect on Mechanical, Thermal, and Morphological Properties. Macromol. Res. 2017, 25, 420-430. [CrossRef]

35. Zhu, J.; Chandrashekhara, K.; Flanigan, V.; Kapila, S. Curing and mechanical characterization of a soy-based epoxy resin system. J. Appl. Polym. Sci. 2004, 91, 3513-3518. [CrossRef]

36. Unnikrishnan, K.P.; Thachil, E.T. Synthesis and Characterization of Cardanol-Based Epoxy Systems. Des. Monomers Polym. 2008, 11, 593-607. [CrossRef]

37. Guo, B.; Jia, D.; Cai, C. Effects of organo-montmorillonite dispersion on thermal stability of epoxy resin nanocomposites. Eur. Polym. J. 2004, 40, 1743-1748. [CrossRef]

38. Qiu, J.J.; Wang, S.R. Enhancing Polymer Performance Through Graphene Sheets. J. Appl. Polym. Sci. 2011, 119, 3670-3674. [CrossRef]

39. Kim, K.S.; Rhee, K.Y.; Lee, K.H.; Byun, J.H.; Park, S.J. Rheological behaviors and mechanical properties of graphite nanoplate/carbon nanotube-filled epoxy nanocomposites. J. Ind. Eng. Chem. 2010, 16, 572-576. [CrossRef]

40. Pressly, T.G.; Keskkula, H.; Paul, D.R. Temperature dependence of the fracture behavior of nylon 6/ABS blends. Polymer 2001, 42, 3043-3055. [CrossRef]

41. Kim, W.J.; Heo, Y.J.; Lee, J.H.; Rhee, K.Y.; Park, S.J. Effect of Atmospheric-Pressure Plasma Treatments on Fracture Toughness of Carbon Fibers-Reinforced Composites. Molecules 2021, 26, 3698. [CrossRef]

42. Park, Y.T.; Qian, Y.Q.; Chan, C.; Suh, T.; Nejhad, M.G.; Macosko, C.W.; Stein, A. Epoxy Toughening with Low Graphene Loading. Adv. Funct. Mater. 2015, 25, 575-585. [CrossRef]

43. Gong, L.X.; Zhao, L.; Tang, L.C.; Liu, H.Y.; Mai, Y.W. Balanced electrical, thermal and mechanical properties of epoxy composites filled with chemically reduced graphene oxide and rubber nanoparticles. Compos. Sci. Technol. 2015, 121, 104-114. [CrossRef]

44. Park, S.J.; Seo, M.K.; Ma, T.J.; Lee, D.R. Effect of chemical treatment of Kevlar fibers on mechanical interfacial properties of composites. J. Colloid Interface Sci. 2002, 252, 249-255. [CrossRef]

45. Park, S.J.; Jang, Y.S.; Rhee, K.Y. Interlaminar and ductile characteristics of carbon fibers-reinforced plastics produced by nanoscaled electroless nickel plating on carbon fiber surfaces. J. Colloid Interface Sci. 2002, 245, 383-390. [CrossRef] [PubMed]

46. Katti, P.; Bose, S.; Kumar, S. Tailored interface resulting in improvement in mechanical properties of epoxy composites containing poly (ether ether ketone) grafted multiwall carbon nanotubes. Polymer 2016, 102, 43-53. [CrossRef]

47. Park, S.J.; Seo, M.K.; Lee, D.R. Studies on the mechanical and mechanical interfacial properties of carbon-carbon composites impregnated with an oxidation inhibitor. Carbon 2003, 41, 2991-3002. [CrossRef]

48. Fu, S.Y.; Feng, X.Q.; Lauke, B.; Mai, Y.W. Effects of particle size, particle/matrix interface adhesion and particle loading on mechanical properties of particulate-polymer composites. Compos. Part B-Eng. 2008, 39, 933-961. [CrossRef] 